\title{
Velocardiofacial syndrome in a mother and daughter: variability of the clinical phenotype
}

\author{
S E Holder, R M Winter, S Kamath, P J Scambler
}

\begin{abstract}
We report a mother and daughter with features of the velocardiofacial (VCF) syndrome and monosomy for $22 \mathrm{q} 11$ identified using molecular techniques. The mother had surgery as a child for a cleft palate and a congenital heart defect, and her facial features were consistent with the diagnosis. The daughter had developmental delay, absent speech, scoliosis, and similar facial features, but no cleft palate or congenital heart defect. These cases illustrate the considerable intrafamilial variability of the phenotype of VCF syndrome.
\end{abstract}

The clinical and molecular diagnosis of this syndrome is discussed. The phenotypic variability of the VCF syndrome means that many cases may be undiagnosed.

( $\mathcal{F}$ Med Genet 1993;30:825-7)

The combination of cleft palate, cardiac anomalies, distinct facial features, and learning disabilities was first described by Shprintzen et $a l^{1}$ in 1978, and was subsequently known as Shprintzen syndrome or velocardiofacial (VCF) syndrome (McKusick No 19243²). Later reports ${ }^{34}$ permitted clear delineation of the clinical phenotype of this autosomal dominant syndrome, but also illustrated the considerable intrafamilial variability, particularly for such features as mental retardation. The face is characterised by a prominent nose with a squared off nasal tip and notched alae nasi. The chin is small. Occasional ocular abnormalities, such as microphthalmia, strabismus, and cataracts, have been described. The cleft palate may be overt or submucous and produces characteristic nasal speech. The cardiac abnormalities vary but usually consist of either a ventricular septal defect, pulmonary stenosis, and double outlet right ventricle, or Fallot's tetralogy.

VCF syndrome has considerable clinical overlap with the DiGeorge syndrome (DGS) (McKusick No $18840^{2}$ ), and this led to patients with VCF being investigated using probes on $22 \mathrm{q} 11 .{ }^{5}$ As with DGS, it was found that the majority were similarly monosomic at $22 \mathrm{q} 11$, using dosage studies and FISH techniques. ${ }^{5-7}$

\section{Department of} Molecular Medicine, Institute of Child

Health, 30 Guilford Street, London WC1N

$1 \mathrm{EH}, \mathrm{UK}$.

$S$ Kamath

P J Scambler

Correspondence to Dr Holder.

Received 21 May 1993. Revised version accepted 14 July 1993. absent speech, global developmental delay, and minor dysmorphic features. She attended with her foster parents with whom she had been placed as her natural mother had a his- tory of psychiatric illness and was unable to provide appropriate care for her child with special needs. However, the patient's mother (case 2) did attend the clinic appointment.

Case 1 was the youngest of three children. One brother had died as an unexplained cot death aged 4 weeks. He had been noted to have a heart murmur in the neonatal period. Her sister is well and attends normal school. She too lives with foster parents. There is no contact with the father, who was said to suffer from narcolepsy, but was otherwise healthy.

Case 1 was born by caesarean section at 36 weeks, birth weight $2700 \mathrm{~g}$. She required tube feeding as an infant because she tended to choke. Her early developmental milestones were delayed, and she did not walk until she was 3 years 6 months of age. She was described as a placid, cooperative, and happy child. She had no speech, but her occasional vocalisations were said to be nasal in character. She communicated by high pitched shouts and grunts, but her laugh was considered normal. She attended a school for hearing impaired children, although she was known not to be deaf. Her comprehension was considered to be good, and she was learning to use Makaton.

On examination she was short (height on the 3 rd centile, weight on the 10th centile for age), with a very pale complexion. She had a thoracic scoliosis, convex to the left, and long tapering fingers. Auscultation was normal. Facially, she had slight facial asymmetry and a small, narrow nose, which looked as if it had been pinched at the end. The facies were rather expressionless. The palate appeared short, but the uvula was normal. No vocalisations were heard throughout the examination. At the time of recent grommet surgery, the comment was made that no submucous cleft palate was present. In view of the suspected diagnosis, an echocardiogram was arranged, which was entirely normal.

Case 2 had a history of having been born with a cleft palate that had been surgically repaired aged 1 year. She also had bilateral talipes equinovarus, for which she wore special boots. She had had cardiac surgery aged 12 years for a 'hole in the heart'. She had attended normal school, but was a low achiever. No other details are available as she is currently receiving psychiatric inpatient care, and for this reason we have been unable to obtain permission to publish her or her daughter's clinical photographs.

She had nasal speech, a large nose with notching of the alae nasi (fig 1) and a squared off nasal tip, and a repaired cleft palate. She also had talipes equinovarus and long, narrow, tapering fingers. 


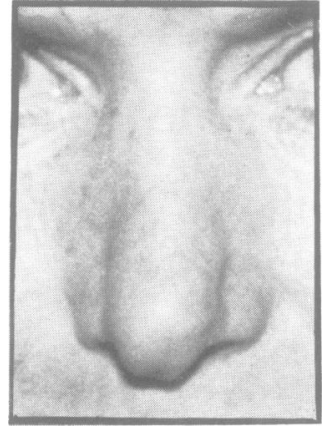

Figure 1 Case 2, nasal configuration. (Permission to publish clinical photographs refused.)
A confident diagnosis of VCF was made in case 2 on clinical grounds. Blood samples were taken for chromosomal and DNA analysis from mother and daughter.

\section{CYTOGENETIC ANALYSIS}

Chromosome analysis on both mother and daughter showed a normal female karyotype $(46, \mathrm{XX})$.

\section{MOLECULAR ANALYSIS}

The probe HD7k is described in the paper by Wadey et al in this issue. Quantitation of Southern hybridisations with probe HD7k was conducted according to our previously published protocol. ${ }^{8}$ However, in place of autoradiography and densitometry, a Molecular Dynamics phosphorimager was used to quantitate hybridisation signals on the filter. The Molecular Dynamics Imagequant software was used throughout. This system eliminates those errors secondary to the non-linear response of film to radiation intensity.

Signal strength ratios (fig 2) were calculated as in the paper by Wadey et al in this issue, and as shown in the table. Hemizygosity is defined as signal strength ratio of $<0.6$ on three occasions.

\section{Discussion}

This mother and daughter illustrate the considerable phenotypic variability in VCF syn-

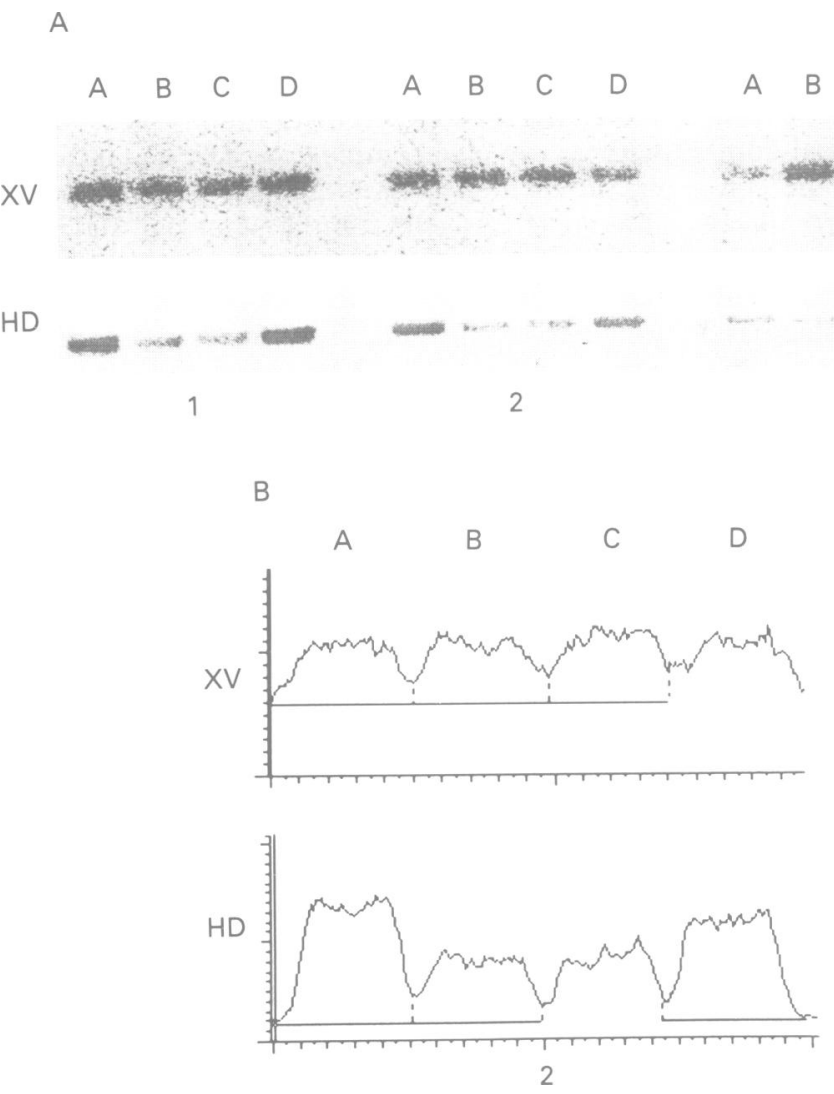

Figure 2 Case 1 and case 2 are both hemizygous for HD7k. HindIII digests of control and test $D N A$ were hybridised with HD7k and XV2c giving single fragments of $8 \mathrm{~kb}$ and $3 \mathrm{~kb}$ respectively. Panel $A$ shows grey scale printer output of scanned images; panel $B$ shows the densitometric profiles obtained for the left hand set of digests. Lane $A=$ control; lane $B=$ case 1 ; lane $C=$ case 2 ; lane $D=$ control.
Calculation of signal strength ratios for fig 2, panel 2.

Average counts XV2c in control lanes $\mathrm{A}+\mathrm{D}$

$=(186+112) / 2=149$

Average counts HD7k in control lanes A+D

$=(424+365) / 2=394 \cdot 5$

Counts XV2c lane $B=196$

Counts XV2c lane $B=196$

Counts XV2c lane $C=201$

Counts HD7k lane $B=225$

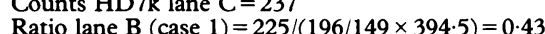

Ratio lane C (case 2) $=237 / 201 / 149 \times 394.5)=0.45$

drome. It is fair to say that the diagnosis of VCF syndrome may not have been suspected in case 1 if her mother had not been present at the appointment. Although her facial features were consistent with the diagnosis, she did not have a cleft palate or a cardiac defect, both cardinal features of VCF syndrome. The diagnosis was confirmed by the finding of hemizygosity at $22 \mathrm{q} 11$ in the mother and daughter using probe HD7k.

In a recent review, ${ }^{3}$ cleft palate was present in $98 \%$ of cases of VCF, and cardiac anomalies in $82 \%$. However, these figures are prone to considerable ascertainment bias and the clinical spectrum of the VCF syndrome continues to expand. ${ }^{7}$

It is possible that a congenital heart defect, such as a ventricular septal defect (VSD), had been present before the child was assessed in the genetic clinic (and an echocardiogram being performed) at 9 years of age. It is known that up to $80 \%$ of small ventricular septal defects close spontaneously during infancy. ${ }^{9}$

The palate was described as short and no cleft was present. Obviously, in a child with little or no speech, the typical hypernasal voice is absent, and therefore unlikely to provide the clue to the diagnosis which this feature can be in some cases. The precise cause for the absence of speech in case 1 remains unclear, but she is not considered a suitable case for pharyngoplasty.

Case 2 has a history of psychiatric illness, for which she is currently receiving inpatient care. The association of late onset psychosis in VCF syndrome has been described previously, ${ }^{710}$ but remains an unexplained phenomenon. It is possible that hemizygosity of the gene coding for catechol-o-methyl transferase (COMT) predisposes to the development of psychiatric illness, as it is deleted in some cases of VCF syndrome. ${ }^{11}$ At present, there is no evidence to suggest that deletion of the COMT gene is responsible for any of the other features present in VCF syndrome. However, further work is required to elucidate the precise genetic defect in this and related disorders, such as DGS.

The phenotype associated with hemizygosity at $22 \mathrm{q} 11$ continues to evolve. Interfamilial variability can perhaps be explained by different sized deletions, as in any contiguous gene syndrome. The intrafamilial variability is harder to explain, and suggests the possibility of modifying genes at separate loci, or extension of an unstable mutation at the VCF locus. Chance association or environmental interaction seem less likely, but are other possible explanations.

We suggest that any family where any single 
feature of either VCF syndrome or DGS is segregating in an autosomal dominant pattern should be investigated using $22 \mathrm{q} 11$ probes. Similarly, any family with an unusual history of apparently unconnected clinical problems (for example, congenital heart disease and mental retardation in one child, immune deficiency in another, and psychiatric illness in a parent) may well be segregating a 22q11 deletion and should be investigated. It seems likely that the true incidence of VCF syndrome is considerably higher than previously suspected.

1 Shprintzen RJ, Goldberg RB, Lewin ML, et al. A new syndrome involving cleft palate, cardiac anomalies, typical facies, and learning disabilities: velo-cardio-facial syndrome. Cleft Palate f 1978;5:56-62.

2 McKusick VA. Mendelian inheritance in man. 9th ed. Baltimore: Johns Hopkins University Press, 1990.

3 Meinecke P, Beemer FA, Schinzel A, Kushnick T. The velo-cardio-facial (Shprintzen) syndrome. Clinical variability in eight patients. Eur $\mathcal{F}$ Pediatr 1986;145:539-44. 4 Stevens CA, Carey JC, Shigeoka AO. DiGeorge anomaly and velocardiofacial syndrome. Pediatrics 1990;85:52630.

5 Scambler PJ, Kelly D, Lindsay E, et al. Velo-cardio-facial syndrome associated with chromosome 22 deletions encompassing the DiGeorge locus. Lancet 1992, 339:1138-9.

6 Kelly D, Goldberg R, Wilson D, et al. Confirmation that the velo-cardio-facial syndrome is associated with haploinsufficiency of genes at chromosome 22q11. Am $\mathcal{F} \mathrm{Med}$ Genet 1993;45:308-12.

7 Goldberg R, Motzkin B, Marion R, Scambler PJ, Shprintzen RJ. Velo-cardio-facial syndrome: a review of 120 patients. Am F Med Genet 1992;45:313-19.

8 Carey AH, Kelly D, Halford S, et al. Molecular genetic study of the frequency of monosomy 22q11 in DiGeorge syndrome. Am ₹ Hum Genet 1992;51:964-70.

9 Hoffman JI, Rudolph AM. The natural history of ventricular septal defects in infancy. Am 7 Cardiol 1965;16:634 53.

10 Shprintzen RJ, Goldberg R, Golding-Kushner KJ, Marion RW. Late-onset psychosis in the velo-cardio-facial syndrome. Am $\mathcal{F}$ Med Genet 1992;42:141-2.

11 Dunham I, Collins J, Wadey R, Scambler PJ. Possible role for COMT in psychosis associated with velo-cardio-facial syndrome. Lancet 1992;340:1361-2. 